Nigerian Journal Of Physiological Sciences 21 (1-2):5-8@Physiological Society Of Nigeria, 2006.

Available online/abstracted at http://www.biolineinternational.org.br/njps; www.ajol.info/journals.njps; www.cas.org

\title{
QT DISPERSION IN DYNAMIC AND STATIC GROUP OF ATHLETES
}

\author{
A. LAWAN, M. A. ALI AND *S. S. DAN BAUCHI
}

Departments of Human Physiology and *Medicine, Faculty of Medicine, Ahmadu Bello University, ZariaNigeria E-mail: lawal_2004ng@yahoo.com Tel: +2348034501012

Summary: Measurement of QT dispersion as calculated from the 12-lead ECG has emerged as a noninvasive assessment for degree of myocardial inhomogeneity. Increased QT dispersion predicts sudden cardiac death in variety of disease states such as acute myocardial infarction and hypertrophic cardiomyopathy. To improve identification of athletes at high risk of sudden death, resting electrocardiograms were performed on 100 dynamic athletes (sprinters, middle and long distance runners), 50 static athletes (Hammer throwers, Weight lifters) and 100-matched control group. QT dispersion was defined as maximum QT interval minus minimum QT interval in a lead. The correlation between QT dispersion and the athletes demographic characteristics revealed that significant correlations existed between QT dispersion and age, SBP, DBP, MBP, body temperature and duration of athletic activity (DAA) ( $<$ 0.05). Similarly, no significant correlation existed between QT dispersion and Heart rate, height, weight and body mass index (BMI). This showed that increased QT dispersion is found in Dynamic and Static group of athletes and is significantly related to duration of athletic activity. This finding could be used for the identification of athletes at high risk of sudden death.

Key words: 12 Lead ECG, QT Dispersion, Athletes and Non-Athletes

\section{Introduction}

Prolongation of the QT interval has been found to predict sudden death in patients with coronary artery disease or alcoholic cirrhosis and to predict cardiovascular death in apparently healthy individuals(Schouten et al, 1991). Recent interest has focused on interlead QT variability (QT dispersion) as a possible predictor of sudden death (Clarkson et al, 1995). Patients with acute myocardial infarction, congestive heart failure and hypertrophic cardiomyopathy who die suddenly have been demonstrated to have increased QT dispersion (Buja and Folino, 1989) As the QT interval on the surface electrocardiogram reflects the duration of the myocardial action potential, it has been proposed that QT dispersion reflects regional variation in ventricular repolarization, and thus electrophysiological substrate for arrhythmias (Merx et al, 1977). However, definitive identification of its independent predictive value requires accurate and reproducible measurement in large number of cases. We decided to look at QT dispersion in dynamic and static athletes in view to identify those at high risk of sudden death.

\section{Methods}

The study population involved 250 adult (18 - 53 years) Nigerians of both sexes. Subjects with history of hypertension, and associated pulmonary disease (e.g. Asthma, Pneumonia), those with previous chest surgery, blood pressure less than $140 / 90 \mathrm{mmHg}$, low body temperature (hypothermia) were excluded from the study. Hospital in-patients, those on any medication at the time of the study, pregnant and puerperal females, alcohol, cigarette and tobacco users were all excluded from the study (Araoye, 1988; Edemeka and Jaja, 1996; Odia and Owhonda, 1999).

The subjects were drawn from 150 athletes (128 males and 22 females) consisting of 100 dynamic athletes (sprinters, middle and long 
distance runners), 50 static athletes (hammer throwers, weight lifters) and 100 - marched control group (68 males and 32 females). All subjects gave informed consent to participate in this study and approval was obtained from the ethical committee of Ahmadu Bello University Teaching Hospital, Zaria.

The aim and the procedure of the test were explained to all the subjects. All qualified subjects had their ECG recording in the Department of Human Physiology. The recording were carried out in the standard way based on the American Heart Association specifications i.e. subject supine (lying uniformly flat), arms by the side, chest electrodes in their correct positions, limb electrodes on wrist and ankles, recorded at $25 \mathrm{~mm} / \mathrm{sec}$, calibrated at $10 \mathrm{~mm} / \mathrm{mV}$. The calibration was consistent and it was done for each tracing and three consecutive cardiac cycles were recorded for each lead and averaged. QT dispersion was defined as maximum QT interval minus minimum QT interval in all the 12 leads.

\section{Data Analysis}

Results were expressed as mean \pm SEM and statistical comparisons between measured variables were carried out using ANOVA and sequential differences among means were calculated at a level of $\mathrm{P}<0.05$.

\section{Results}

Table 1: Shows the age distribution and sex ratio of all the subjects used for this study. Table 2; shows the mean values of QT dispersion in the various leads, and the one way ANOVA test indicated a significant difference $(\mathrm{P}<0.05)$ between the Dynamic, Static group of athletes and the non-athletes.

The correlation between QT dispersion and the athletes demographic characteristics reveal that significant correlation exists between QT dispersion and Age, SBP, DBP, MBP, Body Temperature(BT) and duration of athletic activity (DAA). Similarly, negative correlations existed between QT dispersion and Heart rate, height, weight and BMI as shown in Table 3.

Table 1: Age Distribution Sex Ratio of Subjects

\begin{tabular}{cccc}
$\begin{array}{c}\text { AGE GROUP } \\
\text { (Years })\end{array}$ & $\begin{array}{c}\text { PERCENTAGE } \\
(\%)\end{array}$ & SEX & $\begin{array}{c}\text { PERCENTAGE } \\
(\%)\end{array}$ \\
$18-29$ & $(\mathrm{n}=250)$ & & \\
$30-41$ & 80.0 & MALES & 77.6 \\
$42-53$ & 17.2 & FEMALES & 22.4 \\
\hline
\end{tabular}

Table 2: Mean Qt Dispersion In Dynamic, Static Group of Athletes and Non-Athletes QT Dispersion

\begin{tabular}{ccccc}
\hline LEAD & $\begin{array}{c}\text { DYNAMIC } \\
(\mathrm{ms})\end{array}$ & $\begin{array}{c}\text { STATIC } \\
(\mathrm{ms})\end{array}$ & $\begin{array}{c}\text { NON-ATHLETE } \\
(\mathrm{ms})\end{array}$ & $\mathrm{P}-\mathrm{VALUE}$ \\
\hline $\mathrm{I}$ & 11 & 9 & 1 & $\mathrm{P}<0.05$ \\
$\mathrm{II}$ & 11 & 4 & 0 & $\mathrm{P}<0.05$ \\
III & 8 & 5 & 0 & $\mathrm{P}<0.05$ \\
$\mathrm{~V}_{1}$ & 8 & 2 & 1 & $\mathrm{P}<0.05$ \\
$\mathrm{~V}_{2}$ & 8 & 4 & 0 & $\mathrm{P}<0.05$ \\
$\mathrm{~V}_{4}$ & 7 & 3 & 0 & $\mathrm{P}<0.05$ \\
$\mathrm{~V}_{5}$ & 8 & 4 & 0 & $\mathrm{P}<0.05$ \\
$\mathrm{~V}_{6}$ & 7 & 2 & 0 & $\mathrm{P}<0.05$ \\
\hline
\end{tabular}


QT Dispersion in Athletes and Non-Athletes

Table 3: Correlations (r) between Athletes Demographics, Blood Pressure, Duration Of Athletic Activity (DAA) and QT Dispersion

\begin{tabular}{lll}
\hline PARAMETERS & CORRELATION & $\mathrm{P}-\mathrm{VALUE}$ \\
\hline Age & 0.30 & $\mathrm{P}<0.05^{*}$ \\
Height & -0.04 & $\mathrm{P}>0.05$ \\
Weight & -0.12 & $\mathrm{P}>0.05$ \\
BMI & -0.03 & $\mathrm{P}>0.05$ \\
SBP & 0.20 & $\mathrm{P}<0.05^{*}$ \\
DBP & 0.24 & $\mathrm{P}<0.05^{*}$ \\
MBP & 0.20 & $\mathrm{P}<0.05^{*}$ \\
BT & 0.14 & $\mathrm{P}<0.05^{*}$ \\
HR & -0.04 & $\mathrm{P}>0.05$ \\
DAA & 0.30 & $\mathrm{P}<0.05^{*}$ \\
\hline
\end{tabular}

* Significant.

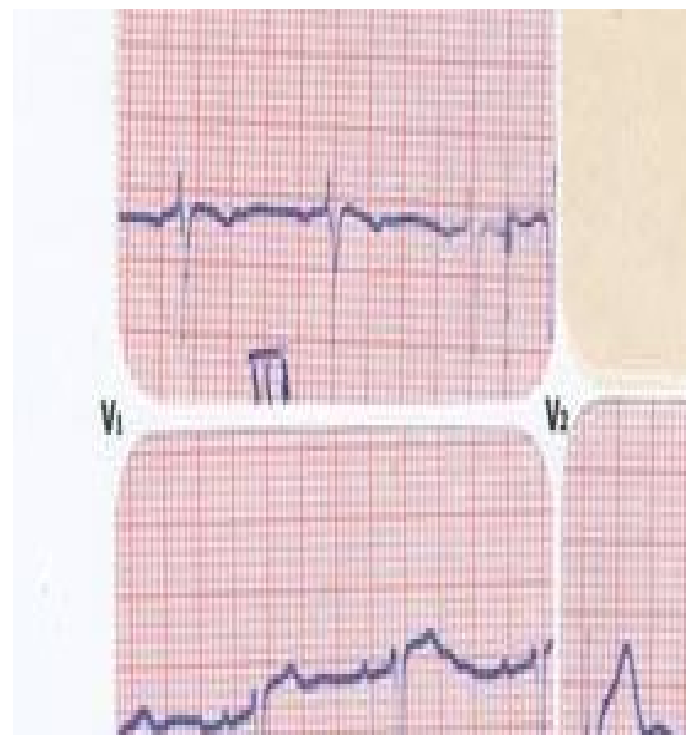

Figure 1: Electrocardiogram Showing Prolonged Qt Interval

(Based on upper limits for heart rate; $Q T C \geq 0.47 \mathrm{Sec}$ in lead II) and $R V H\left(R V_{1}+S V_{5}=15 M M\right)$ in an athlete.

\section{Discussion}

This study presents information obtained from the ECG of Nigerian athletes and nonathletes. About $80 \%$ of the subjects were below the age of 30 years at the time of the study. All subjects were in good physical health and had no history of any major illness.

The QT interval is a measure of the duration of ventricular depolarization and repolarization, while QT dispersion (QTd) is a measure of the variability of the ventricular recovery time (Kassotis et al, 2000). An increase in QTd is found in various cardiac diseases and reflects cardiac autonomic imbalance. It has recently been associated with increased anxiety levels, thereby predisposing affected individuals to fatal heart disease (Nahshoni et al, 2004). The QTd has been suggested as a means of identifying those patients at risk for sustained ventricular tachyarrythmias and sudden cardiac death (SCD). This present study demonstrated that increased QTd is found in both dynamic and static group of athletes and is significantly related to duration of athletic activity $(\mathrm{r}=0.3, \mathrm{P}$ 
$<0.05)$. Information available so far on the effect of heart rate on QTd is scant, but there is no evidence available at present to suggest the QTd varies with $\mathrm{R}-\mathrm{R}$ interval. In this study, a weak relationship was noted between QTd and Heart rate $(r=-0.02, \mathrm{P}>0.05)$.

QT dispersion is increased in patients with heart disease compared to healthy subjects, and prospective studies have suggested that QT dispersion has prognostic value. However, there is a great degree of overlap between healthy subjects and cardiac patients (Maliki and Batchvarov, 2000; Surawicz, 1996). Ecg-figure 1 ; is for a patient with typical Brugada Syndrome who is liable to arrhythmia and sudden death. In conclusion, this finding could be used to improve identification of athletes at high risk of sudden death.

\section{Acknowledgement}

We are grateful to Mr. Dominic O. Okori of the Department of Human Physiology and Tahir of the Department of Medicine for their technical assistance.

\section{References}

Araoye, M. A. ( 1988). The Q wave in healthy adult Nigerians. West African Journal of Medicine. 7(1): $1-6$.

Buja, G., Folino, A. F. (1989). Asystole with syncope secondary to hyperventilation in 3 young athletes. Clinical Electrophysiology. 12: $406-412$.

Clarkson, P. B. M., Naas, A. A. O., McMahon A, Mcleed, C., Struthers, A. D, McDonald, T.
M. (1995). QT dispersion in essential hypertension. Q. J. Med; 88: 327 - 332 .

Edemeka, D. B. U., Jaja, S. I. (1996). Electrocardiogram of well-trained Nigerian Athletes. Nig. Qt. J. Hosp. Med. 6(3): 213 216.

Kassotis, J., Costeas, C., Bedi, A. K., Tolat, A., Reiffel. (2000). Effects of aging and gender on QT dispersion in an overtly healthy population. Pacing Clin. Electrophysiol. 23(7): 1121-116.

Malik, M. Batchvarov, V. N. (2000). Measurement, Interpretation and Clinical Potential of QT Dispersion. J. Am. Coll. Cardiol. 36(6): 1749 - 1766.

Merx, W., Yoon, M. S., Han, J. (1977). The Role of Local Disparity in Conduction and Recovery Time on Ventricular Vulnerability to Fibrillation. Am Heart J. 94: 603 - 610.

Nahshoni, E., Gur, S., Maron, S., Levin J. B., Weizman, A., Hermesh, H. (2004). QT dispersion in patients with social phobia. $J$. Affect Discord. 78(1): $21-26$.

Odia, O. J, Owhonda, G. N. (1999). Sudden death and the competitive athlete: a study of abnormal cardiovascular features in apparently healthy Nigerian athletes. Nig. Postgraduate medical J. 6(2): $78-82$.

Schouten, E. G., Dekker, J. M., Meppelink, P. (1991). QT Interval prolongation predicts cardiovascular mortality in an apparently healthy population. Circulation. 84: $1516-$ 1523.

Surawicz, B. (1996). Will QT dispersion play a role in Clinical Decision-making? J. Cardiovasc Electrophysiol. 7(8): 777-784.

Received: $22 / 2 / 06$

Accepted: 13/10/06 